\title{
Advices about How to Make Career Planning for College Students
}

\author{
Aiqing Meng \\ Dezhou University, Dezhou 253023, China \\ Tel: 86-534-898-5031_E-mail: mengaq1198@163.com
}

\begin{abstract}
To plan college students' own careers, they should deeply understand the society, confirm the struggle target, construct reasonable knowledge structure, actively participate in the social practice, and cultivate good psychological quality to establish firm base for their successful employments.
\end{abstract}

Keywords: Career, Planning, Design

Career planning means one person's all behaviors and activities about his career in his life, and it is the continual experiences about one person's life attitude, value view, and individual will in his life, and it is also one person's change of occupation and post and the realization of working ideal.

College expansion and economic crisis have brought large difficulty of employment, and how should college students plan their careers? How to realize their own life value? For these problems, they will feel confused, which could be presented in two aspects. First, they fell confused in their specialty, individual interest, and future post. Second, they generally don't know to accord with the society. When they select their works or are employed, many of them have not known themselves clearly, the industry and the society. Many students could not realize ideal employment in one time. Therefore, college students should make good preparation before they begin to work, and they should especially plan their career well. How to plan the career? How to make the plans? Following aspect should be emphasized.

\section{Correctly knowing their own specialties and deeply understanding the demand of the society}

Before planning the career, every college students should make clear that "What person I am? What do I want to do? What work can I do? What work can the exterior environment support me?" When colleges instruct their students to plan career, they should make college students know the cultivated target of their specialties, and the direction of the employment, strengthen their self-consciousness of their specialties, cultivate their learning target, and know and love their future works, and colleges should establish firm thinking base for students' future occupation target. In the employment market at present, the existence that supply exceeds demand makes the employing units have special requirements for graduates. Their first objectives are graduates' strong suit in certain specialty, and graduates' main achievements after they enter into the society depend on the base of their specialty, and their initial successes depend on the specialty knowledge learned in the colleges. If college students leave their specialties, they will increase many "burdens" invisibly when they plan their career, which will increase more difficulties to realize their life values. Therefore, college students should not only more deeply study the specialty knowledge what they learned, but also lean more knowledge. The more important is that they should further widen the knowledge about the specialty, grasp and know more knowledge and technologies which are relative to the specialty. At the same time, high vocational students should comprehensively know their own individual characters, interests, favors, and employment ability.

\section{Confirming the target and planning the future}

If one person wants to succeed, he should make concrete and feasible plan, which is the most important basic factor of the success. With the plan, people will not act blindly, and with the plan, people could concretely carry out and implement the plan, and approach to their own target step by step, even realize and exceed the target. The establishment of the plan should refer to the target which should be scientific and feasible and proper. Too high target is difficult to be realized, even could not be realized, and lose people's confidence. And too low target is too easy to be realized, and people will feel chesty and even lose the upward mobility. Only proper and scientific target with feasible plan could stimulate people's fight to realize their own target. College students should realize that the target is the power, and only the struggle could achieve the success. Higher vocational students should learn starting from the most basic and concrete employment post, and only if the tiny post accords with their final employment target, it could be confirmed as their initial employment post. Things should not be distinguished by lowliness and nobleness, and the final results are difficult because peoples' targets are 
different, and the accomplishments of numerous tiny things mean the achievement of the final target, and the realization of the life ideal. Colleges students should fully realize people's career planning should be composed by many tiny things, only they are based on these tiny things, they will accomplish the big thing. In the premise knowing themselves and understanding the society, college students should start from their practice and the demand of the society to confirm the direction of the employment development, make clear the qualities what the employment target needs and the advantages and disadvantages realizing the target.

\section{Constructing reasonable knowledge structure}

College students should not only have certain professional knowledge, but reasonable knowledge structure. Colleges should cultivate students to grasp various qualities, encourage them to participated in various activities, train their own abilities, support them to enhance their comprehensive qualities. Students should actively participate in the part-time jobs and social practices, and engage in the works which are close to their future occupation after school. Students should also actively do more scientific-researches, and enhance their professional ethics, responsibilities, working enthusiasm, and individual frustrated ability in the practice. At the same time, college students should also strengthen their language expression ability, oral foreign language ability, and computer application ability, actively strive for relative certifications about English and computer, and selectively earn credits of other specialties to fulfill themselves. By testing their accumulated abilities and skills, they should modify their individual career planning according to their interests and knowledge quality.

There is no a short cut to establish reasonable knowledge structure, and the basic approaches are only learning and accumulation. The reasonable knowledge structure should not be established one for all, and people have to continually pay hardly labors. Only by proper scientific method and continual struggles, college students will certainly establish and perfect their own knowledge structure, and accumulate good base for their future employments.

\section{Cultivating the practice ability and certain expression ability needed by the career}

College students should also strengthen the learning of professional skill, and they should enhance their employment skill and innovational ability. Students could train their ability and creativity to solve problems independently by the quality development activities, and actively participate in some summer practices about the specialty, and increase the association with their graduated school fellows, and communicate experiences applying for jobs, and study to write resumes and application letters, and increase the channels to collect the working information. College students' comprehensive ability and knowledge are the references for the employing units to select them, and the employing units will check not only their professional knowledge and skills, but their ability to comprehensively utilize knowledge, and their ability to adapt the environment, their ability to integrate the cultures, and their practical ability.

The expression ability is the ability to express their own opinions, ideas, and emotions by the language, and it generally includes the oral expression ability, the word expression ability, and the figure expression ability. For college students, the importance of the expression ability is self-evident. When they enter into the society, they will realize that immediately, and in addition, when they apply for a job or select their jobs, they will deeply feel that. For the writing of the recommendation letters, the answer of the application questions, and the interviews, each part needs certain expression ability. Therefore, when cultivating the expression ability, college students should strive for exact, clear, and lively expression as far as possible.

\section{Actively participating in beneficial social practice and career training, and strengthening the ability to adapt the career}

Career training includes the training of career skills, the adaptability checking of the occupation, and the scientific measurement of occupational intention. College students should first check whether their confirmed career targets are definite and whether their preparations are sufficient. Then, they should train themselves aiming at these problems, accept the training of work selection skills, participate in the recruitment, and check their accumulations and preparations in the practice.

College students should also fully utilize the conditions of the college, look for the information of the employing units, strengthen their employment application skills, train their interview skills, and complete more exercises with sufficient preparations as far as possible.

One person's ability adapting the society is the comprehensive reflection of his quality and abilities, which is close with his moral quality, knowledge skill, activity ability, innovational ability, the ability dealing with the interpersonal relationship, and healthy status. Generally speaking, the college student with higher quality, strong ability, and healthy body and heart could adapt the environment and work as soon as quickly when he enters into 
the society, and even in the bad condition and environment, he could achieve good achievements by his struggles, or turn disadvantageous environment into advantageous environment. Survival of the fittest means that the survival is for the development. Only college students could pay attention to their ability to adapt the society, they could reduce the adapting term and fully exert their intelligences fully after they enter into the society.

\section{Strengthening the self-improvement and training, and cultivating good psychological quality}

College students should cultivate the optimistic habit of enduring hardships and being capable of hard work, and have the host community awareness. One educator said that the person who did anything well was the person with real quality. In fact, in the world of work, people always love those persons with the host community awareness because they could endure hardships and be capable of hard work. Different enterprises have different cultures, but no one enterprise likes the person who want more demands and fewer contributions, have more complaints and less struggles, require more cares and pay less cares. The host community awareness means the awareness of responsibility, and the person with this awareness could be loyal to his enterprise, respect leaders, love works, care about colleagues, think about the benefits of the enterprise at any time, correctly treat his own gain and loss, failure and success. The host community awareness is the awareness of contribution, without too much individual splitting hairs. To enhance their own status in the world of work, college students should depend on their firm quality and their contributions for the enterprise. Any one enterprise will love the person who could actively contribute the organization and the group. For a long time, the person paying more to the enterprise and others will obtain more admittance. So college students should first confirm their feasible career orientation and target, and decompose the target, and then design reasonable career planning, and implement them. By continual struggles and adjustments, they will certainly realize their own career development targets. At the same time, college students' career planning depends on the government, the society, the college, and their won enthusiasm and creativity, and the close integration and comprehensive push of above aspects.

\section{Enhancing the comprehensive quality and cultivating certain management ability}

Though not every college students will engage in the management work after they graduate, but every one will need the management skill in their future works. The modern society has shown that the organization and management ability is not the ability for leaders and managers, but for all people. With the development of the times, the college students not matter which specialty they belong should possess not only profound professional knowledge, but certain ability of organization and management, which is not only the demand of employment, but the objective demand of the times.

The career planning is a long-term engineering, and the planning in the college stage is only a start. Colleges should take this work as the core content and important project of the education, explore and help college students to establish proper employment target, plan their careers, and enhance the science standard and the actual effect of the college students' employment, cooperating with various functional departments.

\section{References}

Feng, Lan. (2004). Psychological Analysis and Countermeasures of College Students' Difficult Employment. Journal of Southwest University for Nationalities (Humanities and Social Science). No. 1, p.408-410.

Xiong, Pingzhuo. (2006). Career Planning. Changsha: Zhongnan University Press. April. 